\title{
Wavy temperature and density distributions formed in snow
}

\author{
Sergey A. Sokratov, ${ }^{*}$ Norikazu Maeno \\ Institute of Low Temperature Science, Hokkaido University, Kita 19, Nishi 8, Sapporo 060, Japan
}

\begin{abstract}
Precise measurements of temperature and density distributions in snow under an applied temperature gradient showed that alternation of evaporation and condensation zones is formed and causes the wavy patterns in quasi-steady temperature and density distributions. In samples with a snow density of $200-500 \mathrm{~kg}^{2} \mathrm{~m}^{-3}$, the wavelength was $3-7 \mathrm{~cm}$ and the amplitude was roughly $2^{\circ} \mathrm{C}$. The present result gives a clue to explaining the wide range of previously measured water-vapor diffusion coefficients in snow.
\end{abstract}

\section{INTRODUCTION}

When a temperature gradient is applied to a snow cover, heat flows and water vapor diffuses towards the colder side. Heat flux is usually divided into three components: conduction in the ice matrix (heat conductivity of porous air is roughly 100 times lower than the heat conductivity of ice which is why heat transported in stagnant air is usually omitted from calculations of heat-transfer characteristics), heat transported by diffusing water vapor and heat transported by air convection. According to previous works, the main part of heat flux without convection is conduction (Yen, 1963; Albert and McGilvary, 1992), though mass transport is one of the most important processes for modifying the internal structure and properties of a natural snow cover. An understanding of the detailed mechanism of the conduction-diffusion coexistence is required to model correctly heat, mass and isotope transport in relation to the metamorphism of snow.

It has been assumed for calculations of the characteristics of the heat conduction and water-vapor diffusion in snow that the steady-state temperature distribution in homogeneous snow was linear, as in other materials. Observed non-linearity of temperature distributions were often related to density variations (e.g. Kondrat'eva, 1954) or some additional phenomena such as air flow (Sturm and Johnson, 1991). The present authors (Sokratov and Maeno, 1997a) also noted that the quasi-steady temperature distributions in snow were not always linear but convex towards the warmer side. Similar non-linear temperature distributions have already been reported by Voytkovskiy and others (1988), but the possibility of inadequate thermal insulation has been anticipated (Colbeck, 1993) and no physical explanations have been given by the authors. The values of possible effective heat conductivities calculated in Sokratov and Maeno (1997a) could not be explained by density variations along the sample length during the experimental run and did not make sense physically. Consequently, we conducted additional experiments which indicated the presence

\footnotetext{
* Present address: Shinjo Branch of Snow and Ice Studies, National Research Institute of Earth Science and Disaster Prevention, Shinjo, Yamagata 996, Japan.
}

of wavy temperature and density distributions in snow. The present paper describes the details of the measurement of wavy temperature distributions together with wavy density distributions formed in snow under a temperature gradient.

\section{EXPERIMENTAL PROGEDURE}

The experimental set-up and procedure have been described in detail in Sokratov and Maeno (1997a). The rectangular snow sample (cross section $18 \times 18 \mathrm{~cm}$ ) was insulated on four sides. One of the uninsulated sides was in contact with a brass tank through which kerosene at a controlled temperature was circulated. The opposite face was maintained at a temperature of $-14^{\circ} \mathrm{C}$. Snow samples were maintained at a uniform temperature before the application of a temperature difference to their opposing faces. After the kerosene flux was switched on, the resulting temperature change in the snow was measured by sensitive thermocouples installed at $2 \mathrm{~cm}$ intervals on the central axis of the snow sample parallel to the direction of heat transfer. The length of the snow samples was $10,20,30$ and $40 \mathrm{~cm}$, and the applied temperature difference to the opposite non-isolated faces was varied from 4.8 to $12.1^{\circ} \mathrm{C}$.

The snow samples were obtained from sifted natural snow. Snow density ranged from 199 to $518 \mathrm{~kg}^{2} \mathrm{~m}^{-3}$. After finishing an experimental run each snow sample was cut into thin slabs (about $1 \mathrm{~cm}$ thick) perpendicular to the direction of heat transfer, and the final density distribution was determined by weighing the slabs. Cutting was done by tense nichrome wires heated electrically. The original density was almost uniform throughout the whole sample, which was checked by cutting of similar pre-prepared snow samples after sifting but before applying the temperature difference.

\section{EXPERIMENTAL RESULTS}

\section{Wavy temperature distributions}

All measured temperature profiles for the different sample lengths and densities showed quasi-steady non-linear temperature distributions as previously reported (Sokratov and Maeno, 1997a). Furthermore, in some snow samples, unex- 


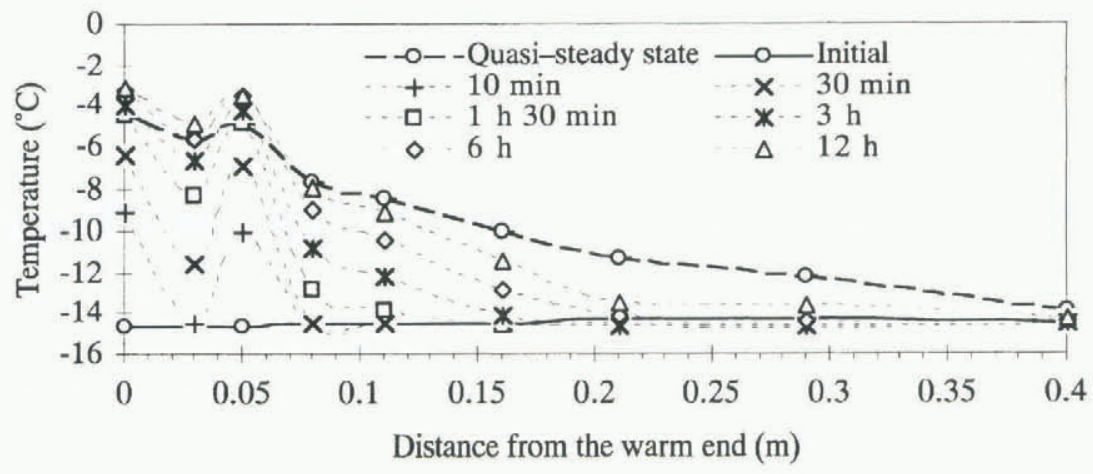

Fig. 1. Temperature distributions in a $40 \mathrm{~cm}$ snow sample. 24 days of $9.4^{\circ} \mathrm{C}$ temperature difference was applied with the cold end kept at $-14.0^{\circ} \mathrm{C}$. Initial snow density $199 \mathrm{~kg} \mathrm{~m}^{-3}$. Time is from the beginning of the experimental run.

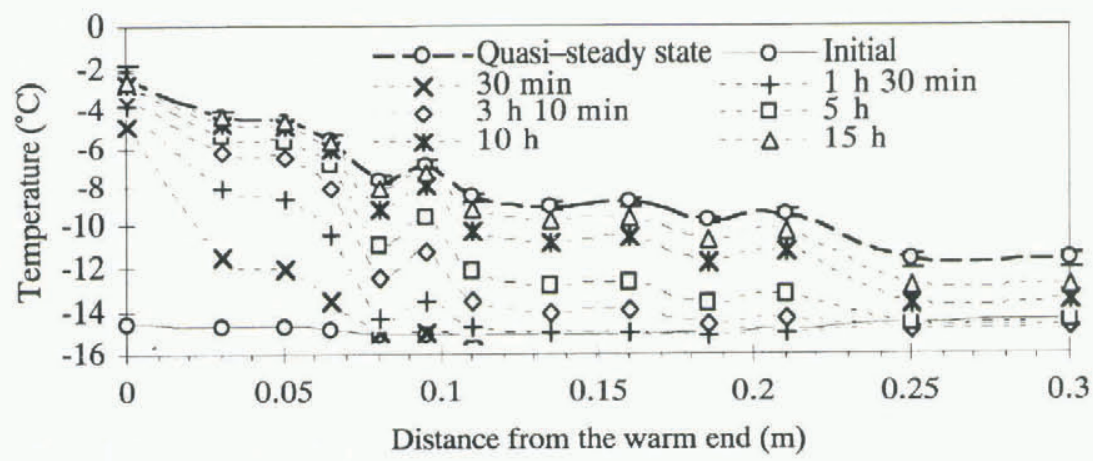

Fig. 2. Temperature distributions in a $30 \mathrm{~cm}$ snow sample. 9 days of $9.2^{\circ} \mathrm{C}$ temperature difference was applied with the cold end kept at $-14.0^{\circ} \mathrm{C}$. Horizontal heat and mass fluxes, initial snow density $4.92 \mathrm{~kg} \mathrm{~m}^{-3}$. Time is from the beginning of the experimental run.

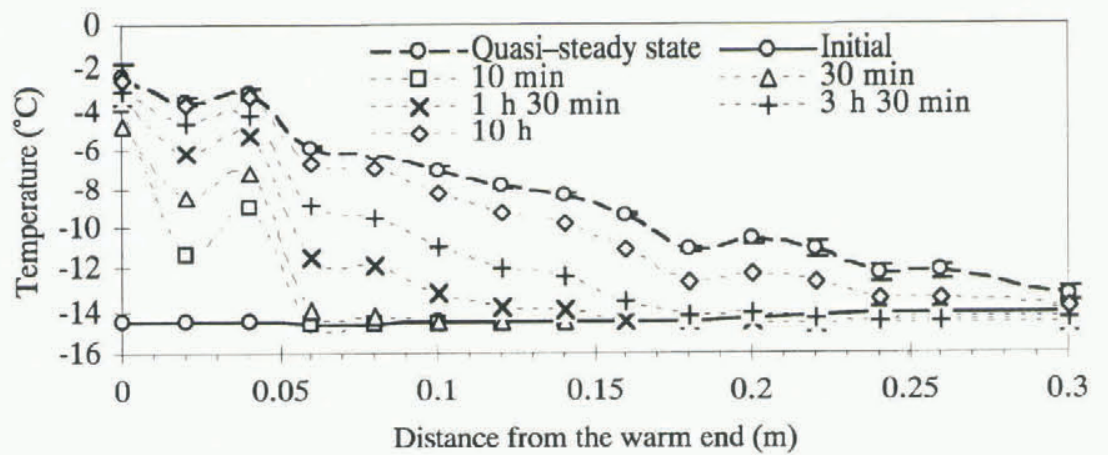

Fig. 3. Temperature distribution in a $30 \mathrm{~cm}$ snow sample. 8 days of $10.9^{\circ} \mathrm{C}$ temperature difference was applied with the cold end kept at $-14.0^{\circ} \mathrm{C}$. Upward heat and mass fluxes, initial snow density $421 \mathrm{~kg} \mathrm{~m}^{-3}$. Time is from the beginning of the experimental run.

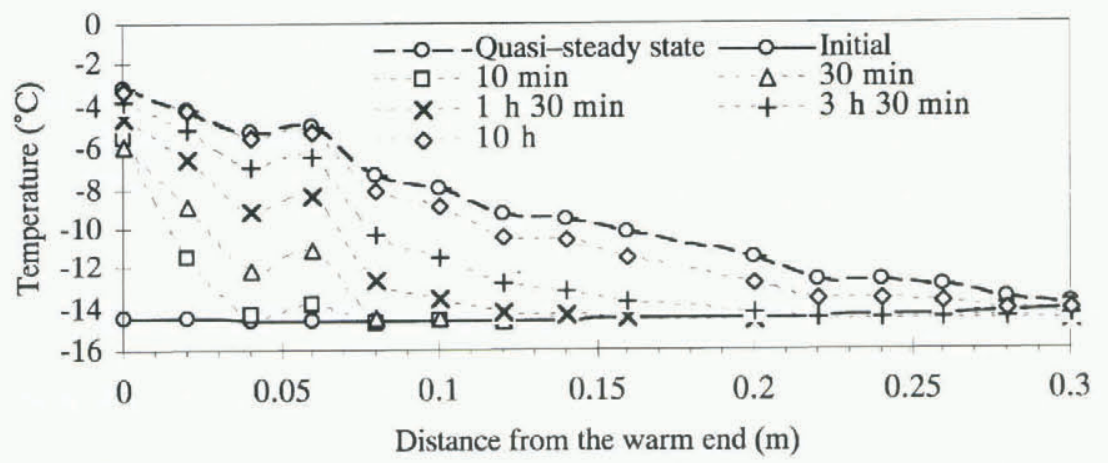

Fig. 4. Temperature distribution in a $30 \mathrm{~cm}$ snow sample. 8 days of $10.7^{\circ} \mathrm{C}$ temperature difference was applied with the cold end kept at $-14.0^{\circ} \mathrm{C}$. Downward heat and mass fluxes, initial snow density $428 \mathrm{~kg} \mathrm{~m}^{-3}$. Time is from the beginning of the experimental run. 
pected waves were observed on the quasi-steady temperature distributions near the warm ends of the samples (Sokratov and Maeno, 1997b). Figure 1 shows a typical example of the temperature distributions in a $40 \mathrm{~cm}$ snow sample, in which a clear wave appeared in a warmer region 10 minutes after beginning the experiment. In this run, the thermocouples were situated at shorter distances only in the warm part, so that the wave was detected. If the wavelength is shorter than the distance between the thermocouples it cannot be recognized. The wavy pattern of temperature distribution had been reported previously for a natural snow cover (Samoylyuk, 1988) but had not been related to the physics of simultaneous heat and water-vapor transfer.

Then several experimental runs were performed with $2 \mathrm{~cm}$ distances between thermocouples for $30 \mathrm{~cm}$ samples of various densities by applying different temperature differences. Figure 2 represents the temperature distribution in a horizontal snow sample, Figures 3 and 4 show the temperature distributions for samples with upward-directed heat flux and downward-directed heat flux, respectively. In Figure 2 we can recognize about five waves in the whole sample. The waves remained as a quasi-steady state during the whole experimental period of 9 days. The experimental runs of Figures 3 and 4 were carried out to check the possibility the waves were caused by thermal convection. Figure 3 shows the case of a vertical upward heat flux in which thermal convection was in theory possible. It is not clear if the wave formation is especially enhanced or not. On the other hand, waves are also evident in Figure 4 in which heat flows vertically downward and no convection could be expected. As waves were formed not only in horizontal and vertical upward fluxes but also in the vertical downward fluxes, the wave formation cannot be attributed to thermal convection.

Each wave consists of a region of temperature decrease in the direction of heat and mass fluxes, and a region where temperature is uniform or even increasing in the direction of fluxes. Measured wavelengths are listed in Table 1 with experimental conditions. In general, all the recognized waves had lengths of about $5 \mathrm{~cm}$ and the temperature variation around the convex trend was roughly $1^{\circ} \mathrm{C}$. In our experiments, the waves appeared in snow almost immediately after the change in temperature of one sample face. Though further experimental work is necessary to define more accurately the wave characteristics, we could not obtain noticeable relations between wavelength and applied temperature gradient, sample length or initial snow density.

\section{Wavy density distributions}

Density distributions obtained by slab weighing showed a wavy pattern similar to the temperature distribution. The density variations were about 10 times larger than density variations observed in the samples before applying a temperature gradient. As the accuracy of the density measurement is not very good and the initial density of each snow sample is not always uniform, the density data were averaged in individual regions of waves recognized on wavy temperature distributions. An example is shown in Figure 5 for the snow sample, the temperature data of which are shown in Figure 2. It is noted that the density decrease and increase correspond to colder and warmer parts in temperature wave, respectively, suggesting that the waves are related to latent-heat exchange in evaporation and condensation zones.

\section{DISGUSSION}

If the wavy pattern of temperature and density distributions is related to condensation-evaporation processes in alternating zones, the mechanism of heat and mass transfer can be interpreted as follows: when temperature on one end of a snow sample with initially uniform temperature distribution is suddenly changed to a higher value, ice grains conduct heat much quicker than the porous air. As a result, water vapor in the porous space near the heat source is undersaturated relative to the grain temperature and evaporation takes place. The concentration gradient formed by the applied temperature gradient forces the evaporated material to be transferred in the direction of heat flux. The temperature of ice grains decreases in the direction of the heat flux, while the amount of water vapor increases in the same direction as more material is added to the water-vapor flux by evaporation. Thus at some distance from the warm end, the water-vapor concentration can be supersaturated to cause condensation of water vapor. The latent-heat release in the condensation zone may warm the surrounding ice, forming the wavy pattern of temperature distributions observed in the present study. The mass transfer from an evaporation zone to a condensation zone may also produce the wavy pattern of final density distributions also noted in the present experiments.

Waves are actually couples of neighboring evaporation and condensation zones where colder temperature zones are associated with evaporation and warmer temperature zones with condensation. The end of one wave is considered as the beginning of the next wave in the direction of heat and mass fluxes. According to the present results, alternation of evaporation-condensation zones is maintained under quasi-steady state conditions at least for the time periods used in the present experimental runs (9-24 days).

\section{CONCLUSIONS}

The main new finding in the present work is the observation of a wavy distribution of temperature and density in snow subjected to a constant temperature difference between two opposing faces. These waves can be explained as the heat

Table 1. Experimental data of wavelength

\begin{tabular}{ccccc}
\hline $\begin{array}{c}\text { Sample } \\
\text { length }\end{array}$ & Temperature & $\begin{array}{c}\text { Temperature } \\
\text { difference } \\
\text { applied } \\
\mathrm{cm}\end{array}$ & $\begin{array}{c}\text { Initial } \\
\text { snow } \\
\text { density } \\
\mathrm{kg} \mathrm{m}^{3}\end{array}$ & Wavelength \\
\hline 10 & ${ }^{-} \mathrm{C}$ & $\mathrm{cm}$ & \\
10 & -14 & 4.8 & 458 & $5-7$ \\
10.5 & -14 & 5.3 & 474 & $5-7$ \\
20 & -14 & 9.2 & 325 & $5-7$ \\
30 & -14 & 7.4 & 500 & $3-5$ \\
30 & -14 & 9.3 & 515 & $5-8$ \\
30 & -14 & 7.4 & 492 & $3-5$ \\
30 & -14 & 14.2 & 492 & $5-7$ \\
30 & -14 & 10.9 & 418 & $6-8$ \\
30 & -14 & 7.3 & 421 & $4-6$ \\
30 & -14 & 7.3 & 428 & $6-8$ \\
40 & -14 & 9.4 & 199 & $6-8$ \\
40 & -14 & 10.7 & 518 & $5-8$ \\
40 & -14 & 12.1 & 325 & $5-8$ \\
& & & & $1-3$ \\
\hline
\end{tabular}




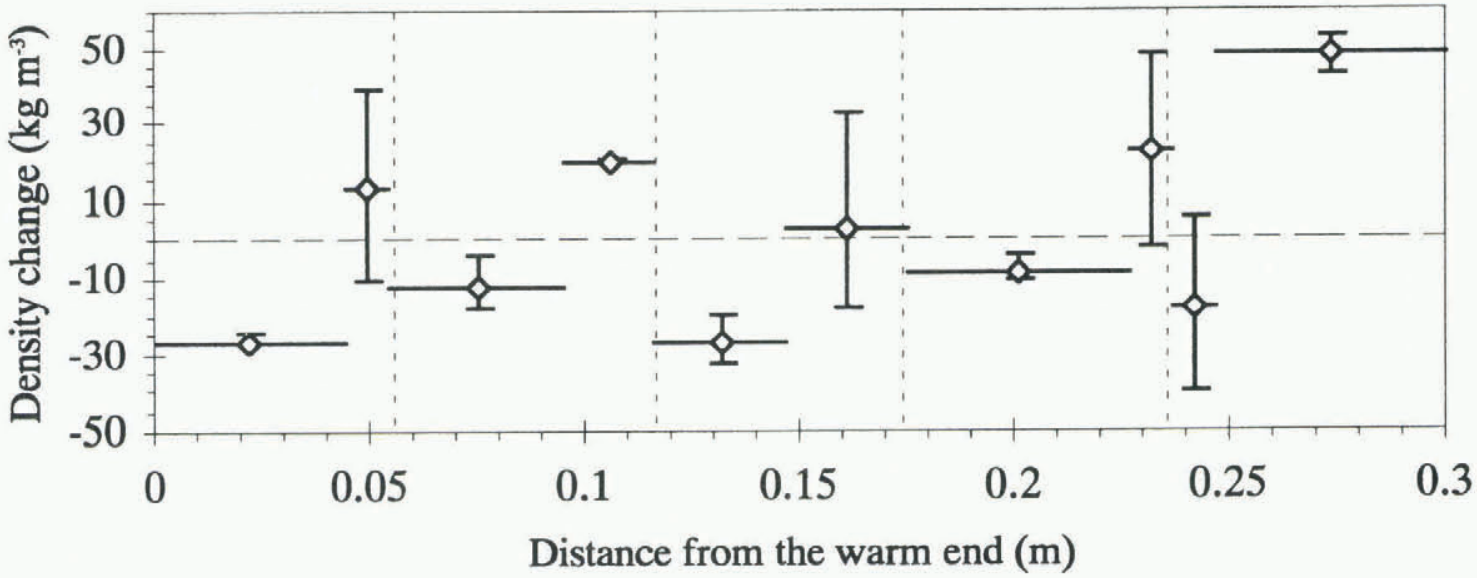

Fig. 5. Local density change measured for the snow sample shown in Figure 2. Averaging distances (horizontal bars) were determined on the basis of recognized temperature waves.

and mass transport in snow, representing alternation of evaporation and condensation zones. Resulting temperature distributions in snow have a wavy pattern of about $5 \mathrm{~cm}$ wavelength, and mass redistribution takes place mostly in these intervals. The present result may explain the wide range of previously measured water-vapor diffusion coefficients from $0.9 \times 10^{-5} \mathrm{~m}^{2} \mathrm{~s}^{-1}$ (Voytkovskiy and others, 1988) to $13.3 \times 10^{-5} \mathrm{~m}^{2} \mathrm{~s}^{-1}$ (Pavlov, 1965). The temperature distribution in snow is a result of the applied heat flux and latentheat release in the evaporation-condensation process and often shows distinct waves. Consequently, the water-vapor diffusion coefficient of snow must be estimated from the real vapor flux and concentration gradient, which vary locally as waves. However, many previous researchers have used an averaged constant temperature gradient through a snow sample, which may lead to incorrect larger water-vapor diffusion coefficients. If we estimate the water-vapor flux from the density change as shown in Figure 5 and the gradient of water-vapor concentration from the local temperature gradient in waves, we can obtain the real water-vapor diffusion coefficient. Such analyses are under way (paper in preparation by Sokratov and Maeno) and typical values are 1$2 \times 10^{-5} \mathrm{~m}^{2} \mathrm{~s}^{-1}$. Thus, the waves can explain long-term contradictions in previously obtained heat conduction and water-vapor diffusion characteristics (Yosida, 1955; Giddings and LaChapelle, 1962; Colbeck, 1993).

\section{ACKNOWLEDGEMENTS}

Sokratov's presence at the Institute of Low Temperature Science and participation in the present work was made possible by a Japanese government (Monbusho) scholar- ship. The authors are grateful to all the staff in ILTS for their help in organizing the laboratory work, especially to Drs H. Narita, K. Nishimura and M. Arakawa.

\section{REFERENGES}

Albert, M. R. and W. R. McGilvary. 1992. Thermal effects due to air flow and vapor transport in dry snow. F. Glaciol., 38(129), 273-281.

Colbeck, S. C. 1993. The vapor diffusion coefficient for snow. Water Resour. Res., 29(1), 109-115.

Giddings, J. C. and E. LaChapelle. 1962. The formation rate of depth hoar. 7. Geophys. Res., 67 (6), 2377-2383.

Kondrat'yeva, A. S. 1954. Thermal conductivity of the snow cover and physical processes caused by the temperature gradient. SIPRE Transl. 22 .

Pavlov, A.V. 1965. Teploobmen promerzayushchikh i protaivayushchikh gruntov s atmosferoy [Heat exchange of freezing and melting grounds with atmosphere]. Moscow, Nauka.

Samovlyuk, V. I. 1988. Raspredelenye temperatury v snezhnoi tolshche [The distribution of temperature in a snow sequence]. Mater. Glyatsiol. Issled. 63, 145-149.

Sokratov, S. A. and N. Maeno. 1997a. Heat and mass transport in snow under a temperature gradient. In Izumi, Nakamura and Sack, eds. Snow engineering: recent advances. Rotterdam, A.A. Balkema, 49-54.

Sokratov, S. A. and N. Maeno. 1997b. Wavy temperature distributions in snow. [Abstract.] Proceedings of the NIPR Symposium on Polar Meteorology and Glaciology 11, 243.

Sturm, M. and J. B. Johnson. 1991. Natural convection in the subarctic snow cover. 7. Geophys. Res., 96(B7), 11,657-11,671.

Voytkovskiy, K. F., V. N. Golubev, A.V. Sazonov and S. A. Sokratov, 1988. Novyye dannyye o koeffitsiyente diffuzii vodyanogo para v snege [New data on diffusion coefficient of water vapour in snow]. Mater, Glyatsiol. Issled. 63, 76-8i.

Yen, Y.-C. 1963. Heat transfer by vapor transfer in ventilated snow. F. Geophys. Res., 68(4), 1093-1101.

Yosida, Z. and colleagues. 1955. Physical studies on deposited snow. I. Thermal properties. Contrib. Inst. Low Temp. Sci., Ser. A 7, 19-74. 